\title{
A Summary of 2018 and What Lies Ahead for Diabetes Therapy in 2019
}

Marc Evans · Fernando Ovalle

Keywords: Continuous glucose monitoring; GLP-1 receptor agonist; Obesity; SGLT2 inhibitors; Type 1 diabetes; Type 2 diabetes

Dear Readers,

We would like to start the year by saying thank you to all of our authors, readers, reviewers, Editorial and Advisory Board members, and everyone who has contributed to $D i$ abetes Therapy over the past 12 months.

The readership of the journal in 2018 was over 750,000, with an average citation rate of 2.76 citations per article. Some of the most highly read articles of 2018 included:

- Effectiveness and Safety of a Novel Care Model for the Management of Type 2 Diabetes at 1 Year: An Open-Label, Non-Randomized, Controlled Study

Sarah J. Hallberg, Amy L. McKenzie, Paul T. Williams, Nasir H. Bhanpuri, Anne L. Peters, Wayne W. Campbell, Tamara L. Hazbun, Brittanie M. Volk, James P. McCarter,

Marc Evans and Fernando Ovalle are joint first authors and co-corresponding authors for this manuscript.

M. Evans ( $\square)$

University Hospital Llandough, Llandough, UK

e-mail: marclyndon1@hotmail.com

F. Ovalle ( $\square)$

University of Alabama at Birmingham, Birmingham, AL, USA

e-mail: fovalle@uabmc.edu
Stephen D. Phinney, Jeff S. Volek

Diabetes Ther (2018) 9:583. https://doi.org/ 10.1007/s13300-018-0373-9.

Over 101,000 downloads to date, 2300 shares and 2 citations.

- SGLT2 Inhibitors in Type 2 Diabetes Management: Key Evidence and Implications for Clinical Practice

John Wilding, Kevin Fernando, Nicola Milne, Marc Evans, Amar Ali, Steve Bain, Debbie Hicks, June James, Philip NewlandJones, Dipesh Patel, Adie Viljoen.

Diabetes Ther (2018) 9:1757. https://doi.org/ 10.1007/s13300-018-0471-8.

Over 11,000 downloads to date, 80 shares and 1 citation.

This article also has an associated Patient and Physician article: Living with Type 2 Diabetes: Patient Commentary in Response to the Paper 'SGLT2 Inhibitors in Type 2 Diabetes Management: Key Evidence and Implications for Clinical Practice'

- EADSG Guidelines: Insulin Therapy in Diabetes.

Bahendeka Silver, Kaushik Ramaiya, Swai Babu Andrew, Otieno Fredrick, Sarita Bajaj, Sanjay Kalra, Bavuma M. Charlotte, Karigire Claudine, Anthony Makhoba.

Diabetes Ther (2018) 9:449. https://doi.org/ 10.1007/s13300-018-0384-6.

Over 11,000 downloads to date. 
We have begun publishing optional Plain Language Summaries alongside the standard scientific abstract to aid understanding and increase dissemination of research to non-experts, including non-specialists, patients, caregivers and others.

We are also very happy to have launched our Patient and Physician Topical Collection in the journal this year, as well as our Guidelines Topical Collection, and Technology in Diabetes Topical Collection. Additionally, we are continuing to grow content in our Practical Approaches to Diabetes Care Topical Collection.

In 2019, we are looking forward to launching podcasts from the Editors-in-Chief to go alongside the journal issues. These podcasts will include a brief discussion of the most important and clinically relevant articles from that issue.

Looking ahead to 2019, this promises to be an equally exciting year of research and innovation in the field of obesity and diabetes. There will be a growing focus on both the pathophysiology of obesity and the development of novel pharmacotherapies aimed at weight reduction. These include high dose receptor agonist (RA) therapies and combination GLP-1, glucagon and GIP receptor agonists. Type 2 diabetes drugs in late stages of development are dominated by mostly "me-too" drugs belonging to the GLP-1 RA and SGLT inhibitor classes. We may see reports of drugs in early development stages including G-protein-coupled receptor 119 agonists, glucokinase activators, protein tyrosine phosphatase 1B inhibitors, and GLP$1 \mathrm{R} /$ glucagon receptor dual agonists.

The field of insulin therapy in diabetes will continue to evolve, with more data around once-weekly basal insulin and a growing number of studies looking at the role of gluco-sensitive insulins.

As ever, 2019 promises to provide its fair share of cardiovascular safety studies and cardiovascular outcome trials (CVOTs) in type 2 diabetes. In particular we are looking forward to the results of the VERITS CV study (ertugliflozin vs placebo; $n=8000$ ), the REWIND results due to be presented in the summer and subsequently expected late in 2019 and the DAPA-HF (dapagliflozin vs placebo; $n=4500$ ), CAROLINA (linagliptin vs glimepiride; $n=6072$ ), and the CREDENCE (canagliflozin vs placebo; $n=4464$ ) trials-this last one looking at the renal and cardiovascular effects of canagliflozin. Following on from the DECLARE TIMI 58 results, there will undoubtedly be much scientific debate as to the contrasting results of the three SGLT-2 inhibitor studies published to date.

In terms of the SGLT-2 inhibitor class, there will also be data generated and published as to the risks, benefits and the potential role of these agents in people with type 1 diabetes. Also, we should see further trials of new glucagon analogues and new insulins. Immunotherapies in earlier stages of development include anti-interleukin receptor-21 and regulatory $\mathrm{T}$ cell therapy both in phase 2 trials.

Technology continues to move fast as well, promising further development in 2019, including new continuous glucose monitors and the development and improvement of closed or semi-closed-loop insulin pump systems.

Additionally, multiple drugs are in late stages of development for obesity and non-alcoholic fatty liver disease which are closely relevant to patients with type 2 diabetes and we should see several trials of some of these drugs start reporting their results during this coming year.

In all, 2018 was a successful year for Diabetes Therapy, and we are excited to continue to develop further in 2019.

\section{ACKNOWLEDGEMENTS}

This commentary is authored by the Editors-inChief of the journal and it has not been peerreviewed.

Funding. No funding or sponsorship was received for this study or publication of this article.

Authorship. All named authors meet the International Committee of Medical Journal Editors (ICMJE) criteria for authorship for this article, take responsibility for the integrity of 
the work as a whole, and have given their approval for this version to be published.

Disclosures. Marc Evans and Fernando Ovalle have nothing to disclose.

Compliance with Ethics Guidelines. This article does not contain any studies with human participants or animals performed by any of the authors.
Open Access. This article is distributed under the terms of the Creative Commons Attribution-NonCommercial 4.0 International License (http://creativecommons.org/licenses/ by-nc/4.0/), which permits any noncommercial use, distribution, and reproduction in any medium, provided you give appropriate credit to the original author(s) and the source, provide a link to the Creative Commons license, and indicate if changes were made. 